Radostaw Kierepka

Uniwersytet Jagielloński

\title{
Gry komputerowe a nowe media: o jednym ze sposobów współdziałania w tworzeniu marki
}

Chociaż rynek gier komputerowych jest jednym z najprężniej rozwijających się na świecie (w 2015 roku odnotował przychód w wysokości 82,4 mld dol. ze wzrostem $8,9 \% \mathrm{w}$ stosunku do analogicznego okresu z roku poprzedniego [Geotrekk S.A. 2016]), wiele osób niezwiązanych w żaden sposób z badaniami rynków lub zjawisk medialnych wciąż postrzega gry jako zwyczajną formę rozrywki, działającą niezależnie od rynku medialnego i nie mającą nań żadnego wpływu.

Na co dzień bez problemu jesteśmy w stanie wskazać ludzi, którzy są użytkownikami nowych mediów, a mimo to grają w gry komputerowe sporadycznie lub nie grają wcale - nie nazwaliby siebie graczami. I choć gry wideo są takim samym medium masowym jak prasa, film czy telewizja, wciąż stawia się je na pozycji „rozrywki dla nastolatków”.

Nawet wielu medioznawców zdaje się nie zauważać roli, jaką gry komputerowe odgrywają w dzisiejszych czasach. Jest to tym bardziej dziwne, że gry już lata temu opuściły salony gier i są dostępne dla niemal każdego użytkownika nowych mediów. Podczas czytania prasy, oglądania telewizji, korzystania z telefonu komórkowego czy przeglądania social media możemy spotkać reklamy lub nawet całe aplikacje umożliwiające zabawę w mniej lub bardziej wymagającą grę. Gry komputerowe są więc nie tylko pełnoprawnym medium, ale również mają wpływ na rozwój pozostałych mediów.

\section{Zmiany form komunikacji międzyludzkiej}

W języku polskim słowo „medium” oraz jego liczba mnoga - „media” - ma wiele znaczeń i jest używane w różnych terminologiach. W potocznym rozumieniu media oznaczają środki służące do komunikowania, zwłaszcza masowego. Mediami nazwiemy więc radio, telewizję, prasę, film, fotografię, muzykę, portale internetowe i niemal wszystkie ich pochodne (Pisarek 2008: 79). Powyższe media jednak pojawiły się w życiu człowieka stosunkowo niedawno, a przecież komunikacja międzyludzka istniała niemal od początku istnienia człowieka. Pierwotnie 
komunikowanie odbywało się wyłącznie twarzą w twarz, na początku przy pomocy sygnałów niewerbalnych. Dopiero później wykształcenie wspólnego języka wzbogaciło prymitywne formy porozumiewania się i pozwoliło na rozkwit komunikacji interpersonalnej (Dobek-Ostrowska 2006: 71). Po pojawieniu się pisma - najpierw obrazkowego, a później fonetycznego - komunikacja nabrała innego znaczenia. Pismo było trwałe, spisane treści zaś zapobiegały przekręceniu lub zapomnieniu na przykład przez posłańca. $Z$ chwilą wynalezienia druku znacząco poszerzył się natomiast krąg odbiorców słowa pisanego. Te trzy symbole komunikacji (mowa, pismo, druk) noszą miano rewolucyjnych, ale jest to szczególny rodzaj rewolucji. Nie niszczy ona bowiem tego, co było przed nią, zaś zwiększa zasięg poszczególnych mediów, a więc i doskonali je (Pisarek 2008: 87).

Na początku XVII wieku pojawiły się pierwsze tygodniki, co wykształciło komunikację masową. Ten nowy model - w przeciwieństwie do relacji face to face - ma charakter pośredni. Pomiędzy nadawcą a odbiorcą występuje pośrednik w postaci medium masowego. Ujarzmienie elektryczności pozwoliło na rozwój kolejnych mediów - telegrafu Samuela Morse'a i telefonu Alexandra Bella. Na początku XX wieku udało się natomiast nadać pierwszą audycję radiową, zaś pierwsza transmisja telewizyjna odbyła się już w 1929 roku (Bajka 2008: 195 i n.). Szybki rozwój telewizji został mocno ograniczony przez wybuch drugiej wojny światowej.

Okres zimnej wojny i wystrzelenie sputnika przez Związek Radziecki zmusiły Amerykanów do stworzenia nowej metody porozumiewania się. W latach sześćdziesiątych XX wieku Paul Baran przedstawił koncepcję komunikacji pomiędzy komputerami. Jej zaletą było to, że zniszczenie jednego komputera nie przerywało działania całej sieci. Do 1980 roku w sieci (nazwanej ARPANET) znajdowało się już ponad czterysta serwerów, zaś w 1983 roku wojsko oddało sieć ARPANET cywilom, samemu zostawiając sobie jego wydzieloną część. Od 1990 roku ARPANET istnieje jako internet. Komunikowanie sieciowe jest typem komunikacji interpersonalnej, w której uczestnicy są pozbawieni kontaktu fizycznego. Łączy w sobie cechy komunikowania interpersonalnego bezpośredniego i masowego pośredniego (Dobek-Ostrowska 2006: 76), ponieważ tak jak w komunikowaniu bezpośrednim dotyczy konkretnych (najczęściej dwóch) osób. Sprzężenie zwrotne jest jednak opóźnione, a sam proces porozumiewania się wymaga obecności pośrednika (medium), czyli na przykład telefonu lub internetu. Ten ostatni umożliwia znacznie szerszą komunikację. Może ona bowiem przebiegać w trybie one-to-one, one-to-many, many-to-many, przy czym użytkownik może na przemian mówić i słuchać (Jakubowicz 2007: 120).

\section{Opowiadanie transmedialne}

Transmedialność lub opowiadanie transmedialne (ang. transmedia storytelling) jest stosunkowo nowym pojęciem, zastosowanym po raz pierwszy przez Henry'ego Jenkinsa w 2006 roku w książce Kultura konwergencji - zderzenie starych i nowych mediów. Jego założenia i warunki, w których występuje, pojawiły się w debatach publicznych już w 1999 roku przy okazji premiery filmu Blair Witch 
Project (Jenkins 2007: 101). Jeśli jednak przyjrzymy się nieco bliżej temu, czym dokładnie jest opowiadanie transmedialne, bez problemu będziemy potrafili wskazać przykłady nawet sprzed 1980 roku.

Dyskusja o produkcie transmedialnym rozpoczęła się po premierze filmu Blair Witch Project, który stał się wielkim fenomenem. Budżet tej produkcji wynosił 60 tys. dol., zaś zysk - $240 \mathrm{mln}$ dol. (IMDb 2016). Stało się tak, ponieważ postrzeganie Blair Witch Project jedynie jako filmu sprawia, że nie dostrzegamy czegoś znacznie większego (Jenkins 2007: 101). Już na rok przed premierą twórcy wykonali szereg działań mających na celu uwiarygodnienie filmu w oczach odbiorców. Po pierwsze uruchomiono stronę internetową, gdzie przedstawiono legendę wiedźmy z Burkittsville (obecna nazwa miasteczka Blair). Sam film był podobno amatorskim nagraniem trójki studentów idących śladem legendy o wiedźmie z Blair, którzy zaginęli, zostawiając po sobie jedynie taśmy filmowe. Obraz był tak zrealizowany, by przekonać widzów, że to, co wymyślili twórcy przed premierą filmu, było prawdą. Rezultat przerósł najśmielsze oczekiwania autorów filmu. Reżyser Eduardo Sánchez w rozmowie z Henrym Jenkinsem powiedział coś, co można uznać za istotę produktu transmedialnego:

[...] jeśli dasz ludziom wystarczająco dużo materiałów do poszukiwań, to zaczną szukać. Nie wszyscy, ale niektórzy na pewno. Ci, którzy to zrobią i wykorzystają do tego cały świat, będą na zawsze twoimi fanami, dadzą ci energię, której nie można kupić przez reklamę [...]. To ta sieć informacji znajdująca się $\mathrm{w}$ zasięgu ręki podtrzymuje zainteresowanie ludzi i sprawia, że ciągle chcą pracować. Jeśli ludzie muszą nad czymś pracować, poświęcą na to więcej czasu i przypisują temu większą wartość emocjonalną (Jenkins 2007: 103).

Podobne zabiegi wykorzystano podczas promocji filmu A.I. Sztuczna inteligencja. (Jenkins 2007: 122). Stworzono grę internetową The Beast, której ukończenie umożliwiało poznanie trzech głównych tajemnic produkcji. Zabawa polegała na tym, że przy pomocy kilku urządzeń medialnych - takich jak strony internetowe, telefony, faksy czy poczty elektroniczne - rozprowadzono ponad 4 tys. komunikatów. I to nie byle jakich, bo uczestnicy zabawy musieli między innymi tłumaczyć z niemieckiego i japońskiego, odszyfrować alfabet Morse'a i Enigmę oraz wiele innych (Jenkins 2007: 282). Fani szybko stworzyli grupę, dzieląc się własnymi wynikami i spostrzeżeniami. Z założenia rozwikłanie zagadek miało zająć trzy miesiące. Wszystkie rozwiązano już pierwszego dnia. Połączenie sił 7 tys. użytkowników dało niespodziewane rezultaty (Jenkins 2007: 124).

Pojęciem związanym nierozerwalnie $z$ opowiadaniem transmedialnym jest pojęcie kultury uczestnictwa, która polega na różnorodnym wykorzystaniu powstałej marki (Filiciak 2006: 177). Najłatwiej jest to zobrazować, biorąc za przykład branżę filmową. Po premierze danego filmu często pojawiają się odwołania, różnego rodzaju fanowskie projekty lub parodie. Do sklepów trafiają gadżety. Z jednej strony te bliższe duchowi pierwowzoru, czyli na przykład figurki przedstawiające bohaterów filmu lub pojazdy, z drugiej natomiast następuje wysyp gadżetów na pierwszy rzut oka wcale niepowiązanych z samym obrazem. Do drugiej kategorii 
można zaliczyć plecaki lub otwieracze do piwa z nadrukowanymi scenami z filmu. Twórcy wychodzą bowiem z założenia, że - oprócz olbrzymiej kampanii marketingowej w mediach - konsumenta można zasypać różnymi gadżetami i innymi tworami powiązanymi bezpośrednio z marką. Poza oczywistym plusem z punktu widzenia marketingu, kultura uczestnictwa nie pozwala marce umrzeć. Szósta część Gwiezdnych wojen - Powrót Jedi ukazała się w 1983 roku, zaś pierwsza część nowej trylogii - Mroczne widmo - w 1999 roku. W ciągu szesnastu lat konsumenci mogliby zdążyć znudzić się Gwiezdnymi wojnami, zapomnieć o nich i na nowo przypominać sobie dopiero przy okazji premiery Mrocznego widma. Nie stało się tak, ponieważ wypuszczane $\mathrm{w}$ tym czasie oryginalne powieści, komiksy, muzyka itd. $\mathrm{z}$ jednej strony generowały zyski, a z drugiej cały czas podtrzymywały markę w świadomości konsumentów (Filiciak 2006: 144).

Idąc tym tropem, Henry Jenkins wyróżnił kilka elementów, które warunkują istnienie produktu transmedialnego:

- worldbuilding - budowanie światów. Zarówno od podstaw, jak i wzbogacanie tych już istniejących. Jest to jedna z ważniejszych cech, gdyż to umiejętność tworzenia światów nadaje historii sens;

- seryjność - polega na podzieleniu historii na kawałki i rozsianiu ich na różne media. Według Jenkinsa idealna postać produktu transmedialnego istnieje wtedy, jeśli każdej części pozwolimy rozwijać się w sferze dla niej najlepszej. W taki sposób historia zostaje wprowadzona na przykład w książce, później zostaje rozwinięta w grach, komiksach i filmach (Filiciak 2006: 111);

- subiektywność - indywidualne odkrywanie świata przez każdego odbiorcę. Odbiorcy oczekują, że nowa część danego produktu rzuci inne światło na przedstawianą historię. Jeśli tak się stanie, konsumenci silniej zwiążą się z marką. Jeśli nie, może dojść do całkowicie odmiennego skutku;

- odtworzenie - cecha pozwalająca na uczestniczenie w historii. Przykładem mogą być fanowskie opowiadania (fanfictions) dziejące się w danym uniwersum lub na przykład modyfikacje tworzone przez graczy.

\section{Opowiadanie transmedialne a gry komputerowe}

Jak to się ma jednak do gier komputerowych? Czy są one w stanie - tak jak filmy - zbudować silną transmedialną markę? Odpowiedź jest jak najbardziej twierdząca. Wystarczy wspomnieć o - sztandarowym moim zdaniem - fenomenie marki Tomb Raider. Początki serii sięgają 1994 roku, kiedy to zrodził się pomysł na "nową grę przygodową, z elementami strzelanin i łamigłówek" (Mańkowski 2010: 243). Dwa lata później - zanim ukończono grę - została zaprezentowana na targach ECTS w Londynie. Trójwymiarowy świat i widok z trzeciej osoby nie były $\mathrm{w}$ zasadzie niczym nowym, zaś sama Lara miała raczej sześcienne kształty i nie można powiedzieć, żeby epatowała seksapilem. W prezentacji gry tkwił jednak pewien haczyk. Na stoisku Tomb Raidera ustawiono motocykl, na którym siedziała ubrana w lateksowy strój modelka z włosami splecionymi w warkocz. Co chwilę 
zsiadała z motoru, żeby zrobić sobie zdjęcie z gośćmi targów. Obecne na targach maskotki i roboty nie mogły konkurować z żywą modelką, której zdjęcia szybko obiegły wszystkie branżowe pisma. W 1996 roku odbyła się premiera gry. Wśród jej plusów wymieniano między innymi muzykę, grafikę, oryginalną fabułę i przede wszystkim główną bohaterkę. Tak narodził się kult Lary Croft. Gracze zaczęli dopytywać o przeszłość Lary, jej rodzinę, a nawet dane osobiste, na przykład datę urodzin. Eidos, który jeszcze przed premierą przejął Core Design (twórców Tomb Raidera), poszedł za ciosem i stworzył oficjalną biografię Lary. Co ciekawe, bohaterka trafiła nie tylko w męskie gusta. Dziewczynki chciały być takie jak ona - silne, mądre, niezależne. Zaczęły powstawać fankluby Lary, a później nawet strony internetowe, na których fanki prezentowały swoje zdjęcia w stroju bohaterki gry (Historia najstynniejszej bohaterki gier. 10 lat z Lara Croft 2006: 44).

Autorzy gry nie ustawali w wysiłkach, aby wydawać kolejne części przygód Lary Croft. Druga część gry, wydana w 1997 roku, odniosła podobny sukces co pierwowzór, jednak przy okazji premiery trzeciej części (1998 rok) nastroje fanów nieco opadły. Wielu graczy uważało, że w stosunku do poprzedniej części zmieniono po prostu za mało. Kolejna, czwarta część (z 1999 roku), pokazała, że autorzy wzięli sobie uwagi fanów do serca. W zamierzeniu była to też ostatnia część cyklu, ponieważ gra kończyła się animacją, w której Lara ginie pod gruzami walącej się piramidy. Mogło to być udane zakończenie historii, gdyby nie to, że rok później ukazał się Tomb Raider V: Chronicles. Piąta część serii opierała się na wspomnieniach bliskich Lary, którzy zebrali się na jej pogrzebie. Gracze uczestniczyli więc w kilku retrospekcjach. Tym razem recenzje graczy i dziennikarzy branżowych nie były jednak aż tak przychylne, więc twórcy dali sobie więcej czasu na stworzenie kolejnej części. Trzy lata później, w 2003 roku do sklepów trafiła szósta część cyklu - Tomb Raider: The Angel of Darkness i nie zostawiła po sobie dobrego wrażenia. Liczba błędów skutecznie uniemożliwiała cieszenie się rozgrywką. Coraz częściej pojawiały się głosy o upadku serii.

W 2004 roku Eidos powierzył produkcję gry amerykańskiemu studiu Crystal Dynamics. Po dwóch latach doszło do premiery siódmej części - Tomb Raider: Legenda. Gra zdobyła świetne noty, chwalono nie tylko fantastyczną grafikę, ale także animację oraz ciekawą fabułę. Seria przeżyła swoiste odrodzenie. W 2006 roku minęło również dziesięć lat od wydania pierwszej części przygód Lary Croft. Na tę okazję wydano odświeżoną wersję pierwszej części gry. W 2008 roku wydano bezpośrednią kontynuację siódmej części serii - Tomb Raider: Underworld. Gra niestety miała dużo błędów, które wpłynęły na ostateczne oceny. Niemniej jednak te wciąż utrzymywały się na poziomie 7-8/10. 
Tabela 1. Średnie oceny gier z serii Tomb Raider (PC) w skali 1-10 wśród najpopularniejszych serwisów internetowych zajmujących się recenzowaniem gier

\begin{tabular}{|l|c|c|c|c|}
\hline \multirow{2}{*}{ Gry z serii Tomb Raider } & \multicolumn{4}{|c|}{ Serwisy internetowe } \\
\cline { 2 - 5 } & Meristation.com & IGN.com & GameSpot.com & Gry-online.pl \\
\hline Tomb Raider I & 9,4 & 9,1 & 8,5 & 9,0 \\
\hline Tomb Raider II & 9,2 & 8,1 & 8,2 & 8,6 \\
\hline Tomb Raider III & 9,3 & 7,7 & 6,9 & 8,3 \\
\hline $\begin{array}{l}\text { Tomb Raider IV: The Last } \\
\text { Revelation }\end{array}$ & 8,5 & 7,0 & 7,4 & 8,4 \\
\hline Tomb Raider V: Chronicles & 7,9 & 6,3 & 6,3 & 6,4 \\
\hline Tomb Raider: Angel of Darkness & 5,6 & 5,3 & 6,1 & 6,4 \\
\hline Tomb Raider: Legenda & 8,2 & 8,2 & 7,8 & 8,5 \\
\hline Tomb Raider: Anniversary & 9,1 & 8,0 & 8,0 & 8,2 \\
\hline Tomb Raider: Underworld & 8,1 & 8,0 & - & 8,2 \\
\hline
\end{tabular}

Źródło: opracowanie własne

W 2009 roku japońska firma Square Enix nabyła Eidos Interactive wraz z prawami między innymi do Tomb Raidera. Przyszłość serii stanęła pod znakiem zapytania, ale w końcu nowi właściciele marki zapowiedzieli powstanie kolejnej gry z cyklu. Twórcy stwierdzili jednak, że wątek Lary jest już przeładowany i zdecydowali się na całkowite zrezygnowanie z dotychczasowego dorobku serii (Kono 2010). Prezes studia Darrell Galagher powiedział: „Powinniśmy zapomnieć o wszystkim, co do tej pory kojarzyło nam się z marką Tomb Raider" (Robinson 2010)1. W 2013 roku odbyła się premiera zupełnie nowej gry Tomb Raider. Gra, choć oczekiwana, niosła ze sobą wiele wątpliwości. W końcu zamiast odważnej akrobatki z parą pistoletów w dłoniach otrzymaliśmy dziewczynę z krwi i kości, która wraz z przyjaciółmi rozbija się na jednej z wysp na Morzu Japońskim. Zobaczyliśmy, jak przestraszona dziewczyna na skutek różnych zdarzeń staje się zaprawioną w boju kobietą. Gra została bardzo ciepło przyjęta i szybko zapowiedziano jej sequel. Rise of Tomb Raider ukazał się 10 listopada 2015 roku na konsolę Xbox One i szybko zaczął zbierać bardzo dobre noty.

Seria Tomb Raider ma na chwilę obecną dwadzieścia lat. Jak już wspomniałem, miała ona swoje wzloty i bardzo bolesne upadki. Za każdym razem jednak pojawienie się nowej gry z serii wywoływało olbrzymie poruszenie wśród graczy. Stało się tak, ponieważ Tomb Raider to nie tylko seria gier, a sama Lara Croft już dawno przestała być wyłącznie bohaterką gry. W końcu postać Lary została zauważona przez Hollywood. W 2001 roku do kin trafil film Lara Croft: Tomb Raider z Angeliną Jolie w roli głównej. Obraz nie zachwycił jednak ani krytyków, ani fanów Lary (Rotten Tomatoes 2016). Nie zmienia to jednak faktu, że pomimo nieprzychylnych recenzji film zarobił niemal trzy razy tyle, ile kosztowała jego produkcja (The Numbers 2016a). W 2003 roku do kin trafiła druga część filmu o podtytule Kolebka życia. Ponownie nie był to film z górnej półki i zarobił „jedynie” $35 \mathrm{mln}$ dol. (The Numbers 2016b).

${ }^{1}$ Tłumaczenia - R.K., jeśli nie zaznaczono inaczej. 
Kilku pisarzy podjęło się napisania książki, aby rzucić nieco światła na wydarzenia, które rozgrywały się pomiędzy poszczególnymi częściami gry. Najpierw ukazała się książka The Amulet of Power Mike'a Resnicka opowiadająca o przygodach pomiędzy grami The Last Revelation i The Angel of Darkness. Kontynuacją książki zajął się już E.E. Knight, pisząc The Lost Cult. Trylogię zamyka książka The Man of Bronze Jamesa Alana Gardnera. Poza wspomnianą wyżej trylogią ukazało się jeszcze kilka książek nawiązujących do serii i zbiory pojedynczych opowiadań (Elrond 2007).

Lara pojawiła się także na łamach komiksów, choć nie od razu jako główna bohaterka. Swój debiut miała w serii Witchblade wydawnictwa Top Cow. Na początku występowała jako pomocnica głównej bohaterki komiksu i była raczej wabikiem mającym podnieść popularność komiksu na fali sukcesu gry. Przewidywania okazały się sukcesem i niedługo potem zdecydowano, że Lara dostanie własny komiks. Każda przygoda była ustalana z wydawcą gry i dzięki temu fani mogli bliżej poznać zarówno cechy charakteru Lary, jak i emocje, które jej towarzyszyły (Elrond 2007). To wszystko pozwalało jeszcze bardziej zidentyfikować się z postacią.

Tomb Raider jest świetnym przykładem opowiadania transmedialnego. Gry, filmy, książki oraz komiksy tworzą olbrzymią historię, którą jako konsumenci możemy przeżywać w różnym stopniu, w zależności od tego, jakiego medium używamy. Wokół nich natomiast nieustannie krążą pozostałe aspekty kultury uczestnictwa powiązane z marką, które ją podtrzymują - gadżety, fanowskie opowiadania, cosplayerzy, parodie, nawiązania itp.

Warto przy okazji wspomnieć o innych markach, które są rozwijane jako opowiadania transmedialne. Sztandarowy produkt firmy Blizzard Entertainment - czyli Warcraft - to seria, która zaczynała od gry dla jednego gracza (Blizzard Enternainment 1994). Następnie w 2004 roku umożliwiła graczom zgłębiać świat w grze MMO (Massive Multiplayer Online - gra, w której w jednym momencie uczestniczy wielu graczy za pośrednictwem internetu) World of Warcraft, książkach (między innymi Warcraft: Dzień smoka, Warcraft: Władca klanów), grach karcianych i planszowych oraz w mającym premierę w 2016 roku filmie - Warcraft: Początek.

Podobnie jest w przypadku japońskiej serii survival horrorów Resident Evil. Od jej debiutu w 1996 roku doczekaliśmy się jedenastu gier z kanonu głównego (wliczając $\mathrm{w}$ to reedycje) oraz osiemnastu gier z kanonów pobocznych (wliczając gry dostępne na konsole przenośne), sześciu filmów aktorskich oraz dwóch filmów animowanych (Wikipedia 2016). Ponadto do marki Resident Evil należą liczne nowelizacje (Resident Evil Wiki 2015) i komiksy (Resident Evil Wiki 2016).

To tylko kilka przykładów olbrzymich marek, które z gier przekształciły się w symbole popkultury rozpoznawalne na całym świecie.

To jednak nie gry komputerowe są czynnikiem gwarantującym sukces produktu transmedialnego. Produkt transmedialny może z powodzeniem budować markę bez pomocy gier komputerowych i odwrotnie - produkt promowany przy pomocy gier niekoniecznie musi gwarantować powodzenie marki. Gry wideo jednak wpływają na sferę emocjonalną gracza, nie są natomiast zwykłym przedstawieniem historii. Dzięki temu gracz może ulec immersji, czyli niejako „przenikaniu” do innej rzeczywistości (Filiciak 2006: 62). Immersji można również doświadczyć, zagłębiając 
się w książkę lub oglądając film. Możliwość sterowania poczynaniami bohatera, a więc decydowanie o przebiegu historii, znacznie tę immersję pogłębia.

Jednym z przykładów produktu transmedialnego zbudowanego pierwotnie na medium pisanym, a następnie rozpropagowanego przy pomocy gry jest polski Wiedźmin. O ile opowiadania i saga o wiedźminie autorstwa Andrzeja Sapkowskiego były już niemal od początku bardzo popularne w Polsce i w państwach sąsiednich, to na zachodzie tytuł wciąż pozostawał niedoceniony i był czytany raczej głównie przez koneserów powieści fantasy. W czerwcu 2015 roku pierwszy zbiór opowiadań o wiedźminie - Ostatnie życzenie - znalazł się na liście bestsellerów „New York Timesa” (sol//plw 2015). Bez wątpienia miało to związek z premierą gry Wiedźmin 3: Dziki Gon wydanej 13 maja 2015 roku na komputery osobiste oraz konsole Xbox One i Playstation 4. Gra została bardzo ciepło przyjęta zarówno przez krytyków, jak i graczy i zaledwie pół roku po premierze zdobyła wiele nagród, wśród których znalazła się ta najważniejsza - Golden Joystick Awards dla gry roku (Woldański 2015).

\section{Uwagi końcowe}

Wspomniane przeze mnie przykłady to tylko kilka produktów w całym, liczącym miliardy dolarów rynku. Okazuje się jednak, że gry komputerowe są nie tylko produktami czysto rozrywkowymi, ale także (jeśli nie przede wszystkim) doskonałym silnikiem napędzającym promowanie marki. Najbardziej widoczną zaletą jest olbrzymi zysk, jaki generują produkty transmedialne. Konsument, który da się pochłonąć oferowanemu przez nas światu, nie tylko kupi i poleci nasz produkt, ale także będzie szukał rozwinięcia historii w innych mediach.

Drugą zaletą jest podtrzymywanie świadomości marki. Gadżety, cosplaye, fanowskie modyfikacje i opowiadania przedłużają życie marki i powodują, że nie zatraca się ona w świadomości konsumentów. Dzięki temu możliwe jest wydanie kolejnego produktu nawet po kilku latach przy niesłabnącym na niego popycie.

Wreszcie produkt transmedialny daje korzyści samemu konsumentowi. Nie dostaje on do swojej dyspozycji zamkniętej historii, która skończy się w momencie finału gry. Opowiadanie transmedialne nie tylko snuje historię na różne sposoby, ale również zadaje wiele pytań, które niejako wymuszają na konsumencie szukanie odpowiedzi wśród innych dostępnych mediów.

Na przykładzie marki Tomb Raider można stwierdzić, że gry wideo są w stanie stworzyć bardzo silną markę, która nie tylko będzie rozpoznawalna na całym świecie, ale - co ważniejsze - taką, którą pokochają miliony i która będzie silnie oddziaływała na popkulturę. Lara Croft stała się symbolem łączącym poprzez media zupełnie różnych ludzi na całym świecie. Bo gdyby nie media, jak wielu ludzi usłyszałoby o bohaterce?

Tomb Raider jest tylko jednym z przykładów, który jasno mówi, że gry nie powinny pozostawać wyłącznie w obszarze rynku gier. Przenikanie się rynku wirtualnej rozrywki z rynkiem mediów jest czymś wręcz pożądanym. Gra komputerowa 
daje możliwość większej immersji, będąc przy okazji impulsem do zjednoczenia pozornie odseparowanych od siebie mediów masowych. Internet, telewizja, film, prasa (komiks), literatura, a nawet muzyka opowiadają jedną wielką historię na różne, ale przy okazji charakterystyczne dla siebie sposoby. Ciekawa opowieść pociąga za sobą większe zainteresowanie innymi mediami, co przekłada się z kolei na pieniądze i rozwój tych mediów. Dzięki temu przedstawiana historia nie kończy się wraz z napisami końcowymi gry lub filmu, ale trwa, dopóki znajdą się ludzie gotowi uczestniczyć w danym uniwersum.

\section{Literatura:}

Bajka Z., 2008, Historia mediów, Kraków: Wydawnictwo i Drukarnia Towarzystwa Słowaków w Polsce.

Dobek-Ostrowska B., 2006, Komunikowanie polityczne i publiczne. Podręcznik akademicki, Warszawa: PWN.

Elrond, 2007, O Larze słów kilka - część VI, http://www.gry-online.pl/S013.asp?ID=34314 [dostęp: 6.10.2016].

Filiciak M., 2006, Wirtualny plac zabaw. Gry sieciowe i przemiany kultury wspótczesnej, Warszawa: Wydawnictwa Akademickie i Profesjonalne.

Geotrekk S.A., 2016, Relacje inwestorskie - elektroniczna rozrywka i gry wideo, http://inwestor. geotrekk.pl/otoczenie-grywideo.html [dostęp: 6.10.2016].

Goban-Klas T., 2005, Cywilizacja medialna: geneza, ewolucja, eksplozja, Warszawa: WSiP.

Historia najstynniejszej bohaterki gier. 10 lat z Lara Croft, 2006, „Komputer Świat GRY” nr 8.

Hopfinger M. (red.), 2005, Nowe media w komunikacji społecznej w XX wieku. Antologia, Warszawa: Oficyna Naukowa.

IMDb, 2016, Blair Witch Project - Box Office, http://www.imdb.com/title/tt0185937/business [dostęp: 6.10.2016].

Jakubowicz K., 2007, Media publiczne: początek końca czy nowy początek?, Warszawa: Wydawnictwa Akademickie i Profesjonalne.

Jenkins H., 2007, Kultura konwergencji. Zderzenie starych i nowych mediów, tłum. M. Bernatowicz, M. Filiciak, Warszawa: Wydawnictwa Akademickie i Profesjonalne.

Kono, 2010, Szczegóty na temat najnowszej części Tomb Raidera, http://www.gry-online.pl/S013. asp? ID =55567 [dostęp: 1.10.2016].

Mańkowski P., 2010, Cyfrowe marzenia. Historia gier komputerowych i wideo, Warszawa: Wydawnictwo Trio-Collegium Civitas.

Noga H., 2005, Bohaterowie gier komputerowych. Implikacje pedagogiczne, Kraków: nakładem autora.

Pisarek W., 2008, Wstęp do nauki o komunikowaniu, Warszawa: Wydawnictwa Akademickie i Profesjonalne.

Resident Evil Wiki, 2015, Resident Evil series, http://residentevil.wikia.com/wiki/Resident_ Evil_series [dostęp: 4.10.2015].

Resident Evil Wiki, 2016, Resident Evil: The Official Comic Magazine, http://residentevil.wikia. com/wiki/Resident_Evil:_The_Official_Comic_Magazine [dostęp: 4.10.2016].

Robinson M., 2010, New Tomb Raider Unveiled, http://www.ign.com/articles/2010/12/06/new-tomb-raider-unveiled [dostęp: 1.10.2016]. 
Rotten Tomatoes, 2016, Lara Croft: Tomb Raider, https://www.rottentomatoes.com/m/lara_cro$\mathrm{ft}$ tomb_raider [dostęp: 1.10.2016].

sol//plw, 2015, Sapkowski na liście bestsellerów „New York Timesa”, http://www.tvn24.pl/kultura-styl,8/sapkowski-na-liscie-bestsellerow-new-york-timesa-wiedzmin,550133.html [dostęp: 6.10.2016].

Surdyk A., Szeja J. (red.), 2008, Kulturotwórcza funkcja gier. Gra w kontekście edukacyjnym, społecznym i medialnym, Poznań: Wydawnictwo Naukowe UAM.

The Numbers, 2016a, Lara Croft: Tomb Raider (2001), http://www.the-numbers.com/movie/ Lara-Croft-Tomb-Raider [dostęp: 6.10.2016].

The Numbers, 2016b, Lara Croft: Tomb Raider: The Cradle of Life (2003), http://www.the-numbers.com/movie/Lara-Croft-Tomb-Raider-The-Cradle-of-Life [dostęp: 6.10.2016].

Wikipedia, 2016, Resident Evil (seria), https://pl.wikipedia.org/wiki/Resident_Evil_(seria) [dostęp: 4.10.2016].

Woldański B., 2015, Golden Joystick Awards 2015 rozdane. Wiedźmin 3 gra roku!, http://pclab.pl/ news66679.html [dostęp: 6.10.2016].

Filmy:

Bont J. de, 2003, Lara Croft Tomb Raider: The Cradle of Life.

Jones D., 2016, Warcraft: Początek.

Lucas G., 1983, Star Wars Episode VI: Return of the Jedi.

Lucas G., 1999, Star Wars Episode I: The Phantom Manace.

Myrick D., Sánchez E., 1999, Blair Witch Project.

Spielberg S., 2001, Artificial Intelligence: AI.

West S., 2001, Lara Croft: Tomb Raider.

Ludografia:

Blizzard Enternainment, 1994, Warcraft: Orcs \& Humans, Cenega S.A.

Blizzard Entertainment, 2004, World of Warcraft, CD Projekt.

CD Projekt Red, 2015, Wiedźmin 3: Dziki Gon, CD Projekt.

Core Design, 1996, Tomb Raider I, Cenega.

Core Design, 1997, Tomb Raider II, Cenega.

Core Design, 1998, Tomb Raider III: Adventures of Lara Croft, Cenega.

Core Design, 1999, Tomb Raider IV: The Last Revelation, Cenega.

Core Design, 2000, Tomb Raider V: Chronicles, Cenega.

Core Design, 2003, Tomb Raider: The Angel of Darkness, Cenega.

Crystal Dynamics, 2006, Tomb Raider: Legenda, Cenega.

Crystal Dynamics, 2008, Tomb Raider: Underworld, Cenega.

Crystal Dynamics, 2013, Tomb Raider, Cenega.

Crystal Dynamics, 2015, Rise of Tomb Raider, Cenega.

\section{Abstrakt}

Gry komputerowe są postrzegane jako produkt czysto rozrywkowy, który nie ma żadnego związku z innymi mediami, takimi jak telewizja, film czy nawet książki. Jako konsumenci wciąż szukamy nowych wrażeń. Jedną z metod, które pomogą doświadczyć nam czegoś nowego i świeżego, jest opowiadanie transmedialne. Celem tekstu jest pokazanie, jak wielki wpływ mają gry komputerowe na rozwój nowych mediów i marek. 


\section{Słowa kluczowe}

gry wideo, opowiadanie transmedialne, nowe media, marka

\section{Summary}

Video Games and New Media: On One of the Methods to Cooperate in Creating a Brand

Computer games have been considered as a stricte entertaining product for teenagers who has no connection to other media like television, film or even books. As a group of customers we are still looking for new thrills. One of the methods that could allow us to experience something new and fresh is create transmedia storytelling. The aim of the text is to show how strong impact computer games coud have on new media and brands.

\section{Keywords}

video games, transmedia storytelling, new media, brand 